\title{
不同氮磷比处理对甘草生长与生态化学计量特征 的影响
}

\author{
黄菊莹 $^{*}$ 余海龙 $^{2}$ 王丽丽 ${ }^{2}$ 马凯博 ${ }^{2}$ 康扬眉 $^{2}$ 杜雅仙 ${ }^{2}$ \\ ${ }^{1}$ 宁夏大学环境工程研究院, 银川 $750021{ }^{2}{ }^{2}$ 宁夏大学资源环境学院, 银川 750021
}

摘 要 大气氮 $(\mathrm{N})$ 沉降增加加速了生态系统 $\mathrm{N}$ 循环, 导致生态系统磷 $(\mathrm{P})$ 需求增加。开展不同 $\mathrm{N}: \mathrm{P}$ 处理对荒漠草原植物生长和 生态化学计量特征影响的研究, 不仅可为预测长期大气N沉降增加条件下植物和土壤的相互作用提供新思路, 而且可为全球 变化背景下我国北方草地植被的可持续管理提供科学指导。该文通过2013-2014年针对甘草(Glycyrrhiza uralensis)设立的不同 $\mathrm{N}: \mathrm{P}$ 的盆栽控制试验, 研究了不同 $\mathrm{N}: \mathrm{P}$ 处理对甘草生物量和碳(C)、N、P化学计量学特征(叶片、根系和土壤)的影响, 比较了 $\mathrm{C}: \mathrm{N}: \mathrm{P}$ 化学计量学特征在叶片、根系和土壤 3 个库间的差异和联系, 探讨了土壤C:N:P化学计量比对甘草生长和养分摄取的指 示作用。结果显示: N:P的适当减小降低了土壤和甘草(叶片和根系)的C:P和N:P, 提高了甘草地上和地下生物量, 说明适量的 $\mathrm{P}$ 添加提高了土壤P有效性和甘草P摄取能力、促进了甘草生长和生物量积累。但过低的 N:P处理(高P添加)使土壤C:P和N:P显著 下降, 抑制了甘草对 $\mathrm{N}$ 的摄取, 从而不利于甘草生长; 甘草叶片和根系(尤其叶片) C:N:P化学计量学特征均与土壤 $\mathrm{C}: \mathrm{N}: \mathrm{P}$ 化学 计量学特征存在不同程度的相关性, 意味着土壤C、N、P及其计量关系的改变会直接作用于植物。以上结果表明, 适当的人 为 $\mathrm{P}$ 添加可通过调节土壤和植物叶片 $\mathrm{C}: \mathrm{N}: \mathrm{P}$ 化学计量学特征, 缓解土壤和植物间 $\mathrm{P}$ 的供需压力, 从而减缓长期大气 $\mathrm{N}$ 沉降增加 对荒漠草原群落结构的不利影响。

关键词 生态化学计量特征; 荒漠草原; 甘草; 磷添加

引用格式: 黄菊藏, 余海龙, 王丽丽, 马凯博, 康扬眉, 杜雅仙 (2017). 不同氮磷比处理对甘草生长与生态化学计量特征的影响. 植物生态学报, 41, 325-336. doi: $10.17521 /$ cjpe.2016.0230

\section{Effects of different nitrogen:phosphorus levels on the growth and ecological stoichiometry of Glycyrrhiza uralensis}

HUANG Ju-Ying $^{1 *}$, YU Hai-Long ${ }^{2}$, WANG Li-Li ${ }^{2}$, MA Kai-Bo ${ }^{2}$, KANG Yang-Mei $^{2}$, and DU Ya-Xian ${ }^{2}$

${ }^{1}$ Institute of Environmental Engineering, Ningxia University, Yinchuan 750021, China; and ${ }^{2}$ College of Resources and Environment, Ningxia University, Yinchuan 750021, China

\section{Abstract}

Aims The increase in atmospheric nitrogen $(\mathrm{N})$ deposition has accelerated $\mathrm{N}$ cycling of ecosystems, probably resulting in increases in phosphorus $(\mathrm{P})$ demand of ecosystems. Studies on the effects of artificial N:P treatment on the growth and carbon (C), N, P ecological stoichiometry of desert steppe species could provide not only a new insight into the forecasting of how the interaction between soils and plants responses to long-term atmospheric $\mathrm{N}$ deposition increase, but also a scientific guidance for sustainable management of grassland in northern China under global climate change.

Methods Based on a pot-cultured experiment conducted for Glycyrrhiza uralensis (an N-fixing species) during 2013 to 2014, we studied the effects of different N:P supply ratios (all pots were treated with the same amount of $\mathrm{N}$ but with different amounts of $\mathrm{P}$ ) on aboveground biomass, root biomass, root/shoot ratio, and C:N:P ecological stoichiometry both in G. uralensis (leaves and roots) and in soils. Additionally, through the correlation analyses between biomass and C:N:P ecological stoichiometry in leaves, roots, and soils, we compared the differences among the C:N:P ecological stoichiometry of the three pools, and discussed the indication of C:N:P ecological stoichiometry in soils for the growth and nutrient uptake of G. uralensis.

Important findings The results showed that, reducing $\mathrm{N}: \mathrm{P}$ decreased $\mathrm{C}: \mathrm{P}$ and $\mathrm{N}: \mathrm{P}$ ratios both in G. uralensis (leaves and roots) and in soils but increased aboveground biomass and root biomass of $G$. uralensis, indicating that

收稿日期Received: 2016-07-05 接受日期Accepted: 2017-02-14

*E-mail: juyinghuang@163.com 
low to moderate $\mathrm{P}$ addition increased $\mathrm{P}$ availability of soils and $\mathrm{P}$ uptake of $\mathrm{G}$. uralensis. However, excessive low $\mathrm{N}: \mathrm{P}$ (high $\mathrm{P}$ addition) led to great decreases in soil $\mathrm{C}: \mathrm{P}$ and $\mathrm{N}: \mathrm{P}$ ratios, thus hindering $\mathrm{N}$ uptake and the growth of G. uralensis. C:N:P ratios in the two pools of G. uralensis (especially in leaves) had close correlations with soil $\mathrm{C}: \mathrm{N}: \mathrm{P}$ ratio, indicating that the change in soil $\mathrm{C}: \mathrm{N}: \mathrm{P}$ ratio would have a direct influence on plants. Our results suggest that, through regulating C:N:P ratio in leaves and soils, appropriate amounts of $\mathrm{P}$ addition could balance soil $\mathrm{P}$ supply and plant $\mathrm{P}$ demand and compensate the opposite influences of long-term atmospheric $\mathrm{N}$ deposition increase on the structure of desert steppe.

Key words ecological stoichiometry; desert steppe; Glycyrrhiza uralensis; phosphorus addition

Citation: Huang JY, Yu HL, Wang LL, Ma KB, Kang YM, Du YX (2017). Effects of different nitrogen:phosphorus levels on the growth and ecological stoichiometry of Glycyrrhiza uralensis. Chinese Journal of Plant Ecology, 41, 325-336. doi: $10.17521 /$ cjpe.2016.0230

大气氮 $(\mathrm{N})$ 沉降增加, 是人类面临的一个全球 性气候变化问题(IPCC, 2013), 其生态学效应受到 越来越多科研工作者的关注。一般而言, 在受 $\mathrm{N}$ 限制 的生态系统, 短期或少量N沉降增加可以刺激 $\mathrm{N}$ 矿 化(Jones \& Power, 2012)、促进微生物-酶系统对土 壤有机质和养分的分解(Liu et al., 2010), 从而提高 土壤 $\mathrm{N}$ 和磷 $(\mathrm{P})$ 的有效性。随着长期或过多 $\mathrm{N}$ 沉降, 不 仅生态系统 $\mathrm{N}$ 输入增加, 而且 $\mathrm{N}: \mathrm{P}$ 失衡、系统N饱和 甚至P压力增加(Bobbink et al., 2010; Wardle et al., 2013), 以及植物生长P受限性增强(Yu et al., 2012)。 在石灰性草原生态系统, 研究人员发现N添加显著 提高了土壤磷酸单酯酶活性, 而土壤磷酸单酯酶活 性与土壤有效 $\mathrm{P}$ 含量显著负相关，因此认为长期 $\mathrm{N}$ 沉降增加导致该生态系统 $\mathrm{P}$ 受限性增加; 随着过多 $\mathrm{N}$ 输入, 植物根系和微生物通过分泌较多的磷酸酶 提高植株对土壤P元素的吸收效率, 从而保证植物 的正常生长(Phoenix et al., 2004)。在其他一些生态 系统, 如热带森林生态系统(Zhu et al., 2013)、温带 森林生态系统(Naples \& Fisk, 2010)和沼泽生态系统 (Phuyal et al., 2008), 研究人员也报道了类似的结 果。由于P不仅是细胞间能量传递和核甘酸结构组 成的重要元素, 而且是许多自然生态系统植物生长 的限制因素, 因此P受限性的增加可能会影响到植 物 $\mathrm{P}$ 策略和生态系统P循环, 从而间接地改变生态系 统结构和功能(Bobbink et al., 2010)。

荒漠草原是最旱生的一类草原生态系统, 具有 群落生产力低和稳定性差的特点, 对自然和人类活 动的干扰比较敏感。受气候和地理位置的影响, 宁 夏回族自治区境内分布有大面积荒漠草原, 其植被 生长不仅受 $\mathrm{N}$ 的限制, 而且年际差异大, 导致生态 系统的不稳定性和脆弱性。尽管在荒漠草原监测到 的大气N沉降量低于其他生态系统(Liu et al., 2013),
但是该生态系统本身 $\mathrm{N}$ 沉降临界负荷低(段雷等, 2002), 而且即使是低剂量的 $N$ 添加, 其长期的影响 也是巨大的(Clark \& Tilman, 2008), 因此有必要针 对该生态系统开展大气 $\mathrm{N}$ 沉降效应的模拟研究。 2011-2013年，在国家自然科学基金青年项目的资 助下, 本项目组在宁夏盐池荒漠草原设置了一个 $N$ 沉降增加的野外模拟试验, 探讨了 $\mathrm{N}$ 添加对植物和 土壤碳(C)、N、P化学计量学特征的影响。研究结 果表明, 生长季内物种相对生长速率、群落生物量 和物种数基本在 $10.0 \mathrm{~g} \cdot \mathrm{m}^{-2} \cdot \mathrm{a}^{-1}$ 的 $\mathrm{N}$ 添加下达到最大, 超过 $10.0 \mathrm{~g} \cdot \mathrm{m}^{-2} \cdot \mathrm{a}^{-1}$ 的 $\mathrm{N}$ 添加后, 各指标逐渐降低; 少量N添加对土壤 C、N、P及其化学计量比的影响 较小, 但高 $\mathrm{N}$ 添加提高了土壤速效 $\mathrm{N}$ 含量、降低了速 效P含量(Huang et al., 2016; 黄菊荣和余海龙, 2016), 这意味着高 $\mathrm{N}$ 添加可能提高了荒漠草原 $\mathrm{P}$ 受限性。那 么, 在高 $\mathrm{N}$ 添加的基础上施 $\mathrm{P}$ 将如何影响荒漠草原 植物生长和化学计量学特征? P添加是否可以缓 解 $\mathrm{N}$ 添加引起的 $\mathrm{P}$ 受限性增加? 土壤养分受限性 转变又将如何作用于植物? 这些问题都值得我们 进行深入研究。

\section{1 研究地区和研究方法}

\section{1 研究区概况}

控制试验开展于宁夏回族自治区盐池县城郊 乡四墩子草原站围栏草地, 地理位置为 $37.82^{\circ} \mathrm{N}$, $107.50^{\circ} \mathrm{E}$ 。该区位于毛乌素沙地西南边缘, 为黄土 高原向鄂尔多斯台地过渡地带。海拔在 1380-1 $600 \mathrm{~m}$ 之间, 年平均气温为 $7.7^{\circ} \mathrm{C}, 1$ 月和7月平均气温分别 为 $-8.9{ }^{\circ} \mathrm{C}$ 和 $22.5{ }^{\circ} \mathrm{C}$, 年降水量和年蒸发量分别为 289.4 和 $2131.8 \mathrm{~mm}$, 为典型大陆型气候。主要土壤 类型为干旱土(FAO制), $\mathrm{pH}$ 值偏高(部分区域 $\mathrm{pH}$ 值可 超过9.0)。植被类型为荒漠草原, 植物群落结构简单, 
物种组成以草本和小灌木为主, 如牛枝子(Lespedeza potaninii)、老瓜头(Cynanchum komarovii)、白草 (Pennisetum centrasiaticum)、粘隐子草(Cleistogenes squarrosa)、冰草(Agropyron cristatum)、针茅(Stipa capillata)、甘草(Glycyrrhiza uralensis)、猫头刺(Oxytropis aciphylla)和柠条锦鸡儿(Caragana korshinskii)等。

试验物种甘草为豆科甘草属(Glycyrrhiza)植物, 是草原带沙生植被类型的建群种和优势种, 也是我 国北方地区重要的防风固沙物种。在宁夏, 野生甘 草主要分布于中东部干旱带起伏的风积沙丘、覆沙 梁地以及较平缓的波状起伏地(李学斌等, 2013)。由 于甘草是常用的大宗药材, 野生甘草多年来受到掠 夺式采挖, 致使野生甘草资源遭到了极大的破坏, 甚至出现严重的资源枯竭。近年来, 随着国家禁挖 政策的执行和甘草资源的市场需要, 甘草的人工种植 得到了广泛的推广。目前, 宁夏已形成了盐池、红寺 堡、平罗、中宁等重点甘草种植区(李学斌等, 2012)。

\section{2 样地设置和试验设计}

不同N:P处理试验于2013-2014年进行。于2013 年4月底, 将 30 根规格为 $16 \mathrm{~cm} \times 50 \mathrm{~cm}$ (直径 $\times$ 高)的 PVC管垂直埋入土中(其顶端露出地面 $3 \mathrm{~cm}$ )。在甘 草自然分布区用铁锹垂直取0-50 cm 土壤, 混匀过 $2 \mathrm{~mm}$ 篎后, 填入 PVC管中, 每根 PVC管装土约 $11 \mathrm{~kg}$ 。甘草幼苗选自盐池县城郊乡二年生人工甘草 示范地, 挖取时尽可能保证每株幼苗长势相同(株高 10-12 cm、基径0.4-0.5 cm、叶片5-6个), 并于 5月上 旬植于PVC管中培养, 每根PVC管中移栽两株幼苗。 两周后, 每根PVC管留苗1株, 开始进行施肥处理。

$\mathrm{N}$ 肥处理强度以2011年在围栏草地内设立的 $\mathrm{N}$ 添加原位试验观察结果为主要依据, 并综合考虑了 甘草的固 $\mathrm{N}$ 特性和区域大气 $\mathrm{N}$ 沉降水平。 $\mathrm{P}$ 肥施用量 以研究区土壤 $\mathrm{P}$ 供给状况和植物 $\mathrm{P}$ 利用效率为主要 依据。每个处理 $\mathrm{N}$ 施入量均为 $10.0 \mathrm{~g} \cdot \mathrm{m}^{-2} \cdot \mathrm{a}^{-1}$, 通过改 变 $\mathrm{P}$ 肥的施用量 $(1.0 、 2.0 、 4.0 、 8.0 、 16.0$ 和 $\left.32.0 \mathrm{~g} \cdot \mathrm{m}^{-2} \cdot \mathrm{a}^{-1}\right)$ 形成 6 个 $\mathrm{N}: \mathrm{P}$ 处理水平: $10.0(\mathrm{~N} 10 \mathrm{P} 1)$ 、 5.0 (N10P2)、2.5 (N10P4)、1.3 (N10P8)、0.6 (N10P16) 和0.3 (N10P32), 每个处理5次重复。所施N肥为含 $34 \% \mathrm{~N}$ 的 $\mathrm{NH}_{4} \mathrm{NO}_{3}$, 所施 $\mathrm{P}$ 肥为含 $51.7 \% \mathrm{P}_{2} \mathrm{O}_{5}$ 的 $\mathrm{KH}_{2} \mathrm{PO}_{4}$ 。2013和2014年每年5-8月中旬, 对各处理 进行相应的 $\mathrm{N}$ 肥和 $\mathrm{P}$ 肥施用。为了尽可能地避免高 $\mathrm{P}$ 肥的毒害、提高 $\mathrm{N} 、 \mathrm{P}$ 肥的利用效率, 以每周 2 次的 频率随水喷施。同时, 采用称重法每 10 天监测 1 次土
壤含水量, 依据移植前的土壤含水量和监测的实时 土壤含水量差值进行补水。

\section{3 样品收集和化学测定}

2014年8月底施肥处理结束后, 在每个PVC管 中用剪刀齐地面剪下甘草地上部分, 并从中随机挑 选出30片健康叶, 与剩余地上部分分别装袋后带回 实验室烘干 $\left(65{ }^{\circ} \mathrm{C}, 48 \mathrm{~h}\right)$ 并称质量。同时, 收集盆内 的甘草根系, 带回实验室去除非目标杂质, 清洗干 净后烘干 $\left(75^{\circ} \mathrm{C}, 48 \mathrm{~h}\right)$ 并称质量。烘干的叶片和根系 经粉碎后测定 $\mathrm{C} 、 \mathrm{~N}$ 和 $\mathrm{P}$ 含量。根冠比为地下生物量 和地上生物量的比值。

甘草收获后, 采用土钻(内径为 $3 \mathrm{~cm}$ )收集了每个 处理0-10 cm 土壤样品, 每根PVC管取3钻。将每根 $\mathrm{PVC}$ 管取出来的土混合均匀, 过 $2 \mathrm{~mm}$ 篎后分为两部 分: 一部分 $4{ }^{\circ} \mathrm{C}$ 保存, 用于有效 $\mathrm{N}$ 和速效 $\mathrm{P}$ 含量测定; 另一部分风干后用于测定土壤有机C、全N和全P含量。

植物和土壤 $\mathrm{C} 、 \mathrm{~N} 、 \mathrm{P}$ 含量的测定主要参考鲍士 旦(2000)主编的《土壤农化分析》。其中, 采用重铬 酸钾容量法-外加热法测定植物和土壤干样有机 $C$ 含 量; 采用凯氏定氮法测定植物和土壤干样全 $\mathrm{N}$ 含量; 分别采用钼锑抗比色法和 $\mathrm{HClO}_{4}-\mathrm{H}_{2} \mathrm{SO}_{4}$ 法测定植物 和土壤干样全P含量; $\mathrm{CaSO}_{4} \cdot 2 \mathrm{H}_{2} \mathrm{O}$ 溶液中浸提后, 采用流动分析仪(Auto Analyzer 3, SEAL Analytical $\mathrm{GmbH}$, Hanau, Germany) 分析新鲜土样无机 N $\left(\mathrm{NH}_{4}^{+}-\mathrm{N}\right.$ 和 $\left.\mathrm{NO}_{3}^{-}-\mathrm{N}\right)$ 含量; 采用 $0.5 \mathrm{~mol} \cdot \mathrm{L}^{-1} \mathrm{NaHCO}_{3}$ 法 测定新鲜土样速效 $\mathrm{P}$ 含量。

\section{4 数据分析}

图的绘制和曲线拟合在SigmaPlot 12.5中完成, 数据的显著性分析由SPSS 13.0 完成。数据分析前, 采用K-S test进行正态分布检验。所有数据均符合正 态分布, 因此采用单因素方差分析的最小显著性差 异法(LSD)比较不同处理间各指标(生物量、根冠比、 C、 N、P含量及其化学计量比)的差异性, 采用 Pearson法分析生物量、根冠比以及C:N:P化学计量 学特征间的相关性。

\section{2 结果和分析}

\section{1 甘草移栽前土壤背景值}

甘草移栽前对PVC管内混匀土进行了本底调查, 结果表明, 土壤有机C、全 $\mathrm{N} 、$ 全P、 $\mathrm{NH}_{4}{ }^{+}-\mathrm{N} 、 \mathrm{NO}_{3}{ }^{-}-\mathrm{N}$ 和速效P含量分别为 $1.8 \mathrm{~g} \cdot \mathrm{kg}^{-1} 、 0.2 \mathrm{~g} \cdot \mathrm{kg}^{-1} 、 0.3 \mathrm{~g} \cdot \mathrm{kg}^{-1}$ 、 $1.2 \mathrm{mg} \cdot \mathrm{kg}^{-1} 、 8.3 \mathrm{mg} \cdot \mathrm{kg}^{-1}$ 和 $13.8 \mathrm{mg} \cdot \mathrm{kg}^{-1}$ (表1)。 
表1 甘草移栽前土壤本底值

Table 1 Basic soil properties before Glycyrrhiza uralensis transplanting

\begin{tabular}{cccccc}
\hline $\begin{array}{c}\text { 土壤有机碳 } \\
\text { Soil organic carbon }\left(\mathrm{g} \cdot \mathrm{kg}^{-1}\right)\end{array}$ & $\begin{array}{c}\text { 土壤全氮 Soil total } \\
\text { nitrogen }\left(\mathrm{g} \cdot \mathrm{kg}^{-1}\right)\end{array}$ & $\begin{array}{c}\text { 土壤全磷 } \\
\text { Soil total phosphorus }\left(\mathrm{g} \cdot \mathrm{kg}^{-1}\right)\end{array}$ & $\begin{array}{c}\mathrm{NH}_{4}^{+}-\mathrm{N}_{(1} \\
\left(\mathrm{mg} \cdot \mathrm{kg}^{-1}\right)\end{array}$ & $\begin{array}{c}\mathrm{NO}_{3}^{-}-\mathrm{N} \\
\left(\mathrm{mg} \cdot \mathrm{kg}^{-1}\right)\end{array}$ & $\begin{array}{c}\text { 土壤速效磷 } \\
\text { Soil available phosphorus }\left(\mathrm{mg} \cdot \mathrm{kg}{ }^{-1}\right)\end{array}$ \\
\hline 1.8 & 0.2 & 0.3 & 1.2 & 8.3 & 13.8 \\
\hline
\end{tabular}

\section{2 不同 N:P处理对甘草生物量和根冠比的影响}

降低施入的 N:P (P添加量增加)提高了甘草地 上生物量、地下生物量和总生物量, 并在 $8 \mathrm{~g} \cdot \mathrm{m}^{-2} \cdot \mathrm{a}^{-1}$ 的 $\mathrm{P}$ 添加下 3 个指标达到最大值 $1.5 、 2.3$ 和 $3.8 \mathrm{~g} \cdot$ plant $^{-1}$, 表明当 $\mathrm{N}: \mathrm{P}$ 处于中等水平时, 甘草具 有较高的生物量, 过高和过低的 $\mathrm{N}: \mathrm{P}$ 都不利于甘 草生物量积累(图1 A、1B、1C)。与地上生物量、 地下生物量和总生物量不同, $8.0 \mathrm{~g} \cdot \mathrm{m}^{-2} \cdot \mathrm{a}^{-1}$ 的 $\mathrm{P}$ 处 理使根冠比与其他处理相比降低了 $21.7 \%-33.1 \%$ (图1D)。

\section{3 不同N:P处理对甘草C、N、P含量及其化学计 量比的影响}

降低施入的 $\mathrm{N}: \mathrm{P}$ 提高了甘草叶片P浓度, 降低了
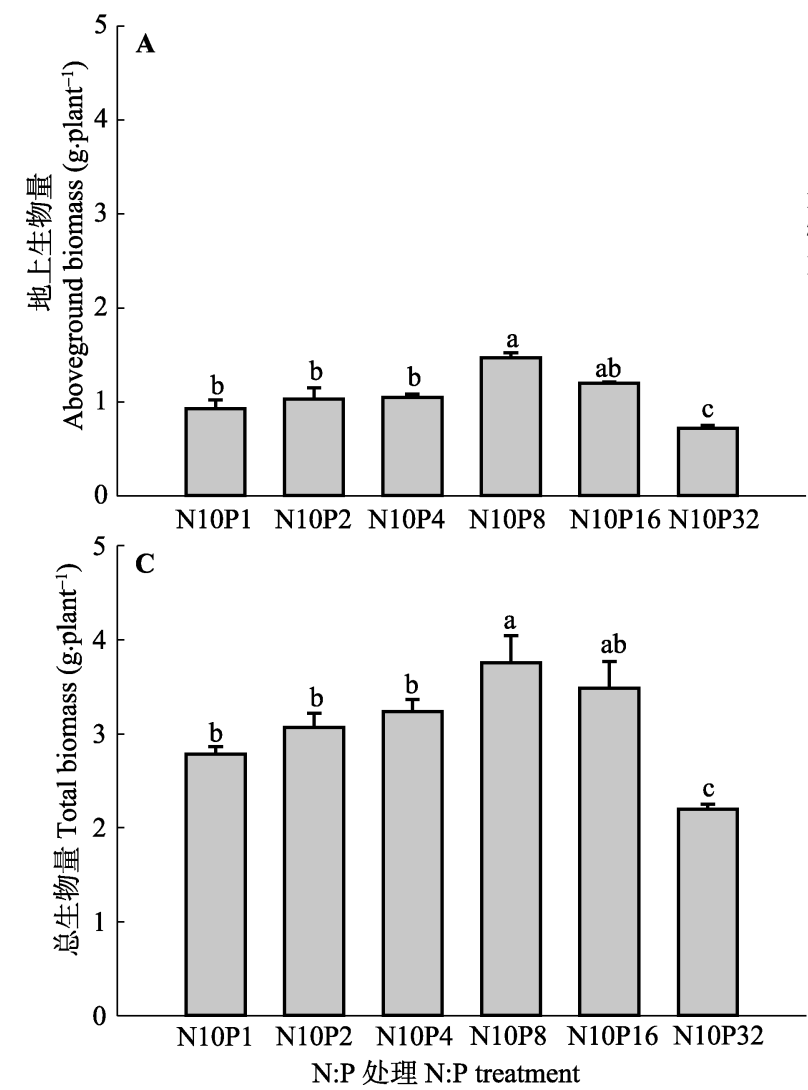

$\mathrm{N}$ 浓度、C:P和 $\mathrm{N}: \mathrm{P}$, 对 C浓度和 $\mathrm{C}: \mathrm{N}$ 的影响无显著的 规律性(图2A、2D)。平均叶片C浓度、N浓度、 $\mathrm{P}$ 浓 度、C:N、C:P和 $\mathrm{N}: \mathrm{P}$ 分别为 $376.6 \mathrm{mg} \cdot \mathrm{g}^{-1} 、 33.1 \mathrm{mg} \cdot \mathrm{g}^{-1}$ 、 $2.8 \mathrm{mg} \cdot \mathrm{g}^{-1} 、 12.2 、 143.5$ 和 12.5 。

降低施入的N:P提高了甘草根系的C浓度、N浓 度、 $\mathrm{P}$ 浓度和 $\mathrm{C}: \mathrm{N}$, 降低了 $\mathrm{N}: \mathrm{P}$ (图3F), 对 $\mathrm{C}: \mathrm{P}$ 的影响 无明显的规律性。平均根系C浓度、N浓度、P浓度、 $C: N 、 C: P$ 和 $N: P$ 分别为 $426.5 \mathrm{mg} \cdot \mathrm{g}^{-1} 、 21.3 \mathrm{mg} \cdot \mathrm{g}^{-1}$ 、 $1.9 \mathrm{mg} \cdot \mathrm{g}^{-1} 、 20.2 、 228.7$ 和 11.4 。

\section{4 不同N:P处理对8月份土壤C、N、P含量及其化} 学计量比的影响

降低施入的 $\mathrm{N}: \mathrm{P}$ 提高了土壤全P和速效 $\mathrm{P}$ 含量 (图4C、4F), 降低了C:P和N:P (图5B、5C), 对其他
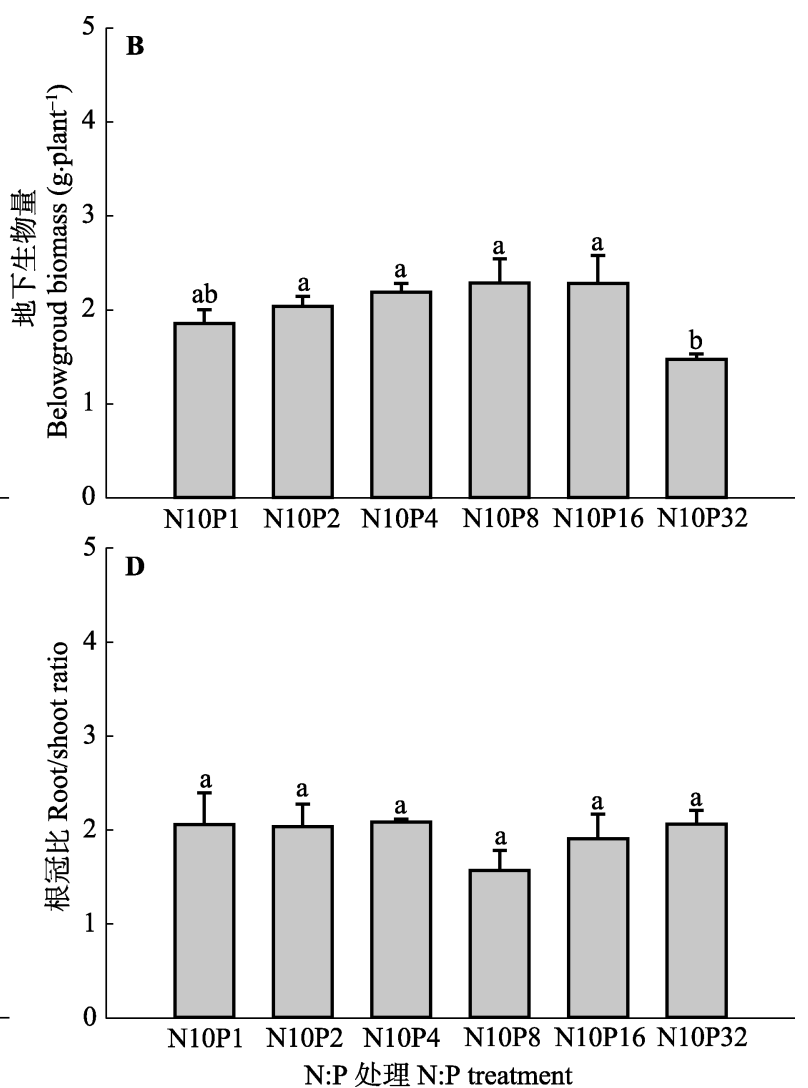

图1 不同氮 $(\mathrm{N})$ 磷 $(\mathrm{P})$ 比处理对甘草生物量和根冠比的影响(平均值标准误差, $n=5)$ ) N10P1、N10P2、N10P4、N10P8、N10P16 和 $\mathrm{N} 10 \mathrm{P} 32$ 代表在统一施用 $10.0 \mathrm{~g} \cdot \mathrm{m}^{-2} \cdot \mathrm{a}^{-1} \mathrm{~N}$ 的基础上, 分别施入 $1.0 、 2.0 、 4.0 、 8.0 、 16.0$ 和 $32.0 \mathrm{~g} \cdot \mathrm{m}^{-2} \cdot \mathrm{a}^{-1}$ 的 $\mathrm{P}$ 。不同小写字母表 示N:P处理间指标差异显著 $(p<0.05)$ ，相同字母表示差异不显著 $(p>0.05)$ 。

Fig. 1 Effects of nitrogen (N):phosphorus (P) level on root and aboveground biomass and root/shoot ratio of Glycyrrhiza uralensis $($ mean $\pm S E, n=5)$. N10P1, N10P2, N10P4, N10P8, N10P16, and N10P32 represent all pots treated with $10.0 \mathrm{~g} \cdot \mathrm{m}^{-2} \cdot \mathrm{a}^{-1}$ amount of N but with different amounts of P: 1.0, 2.0, 4.0, 8.0, 16.0, and $32.0 \mathrm{~g} \cdot \mathrm{m}^{-2} \cdot \mathrm{a}^{-1}$, respectively. Different lowercase letters indicate significant difference $(p<0.05)$ between indices within N:P levels. The same lowercase letters indicate insignificant differences $(p>0.05)$. 

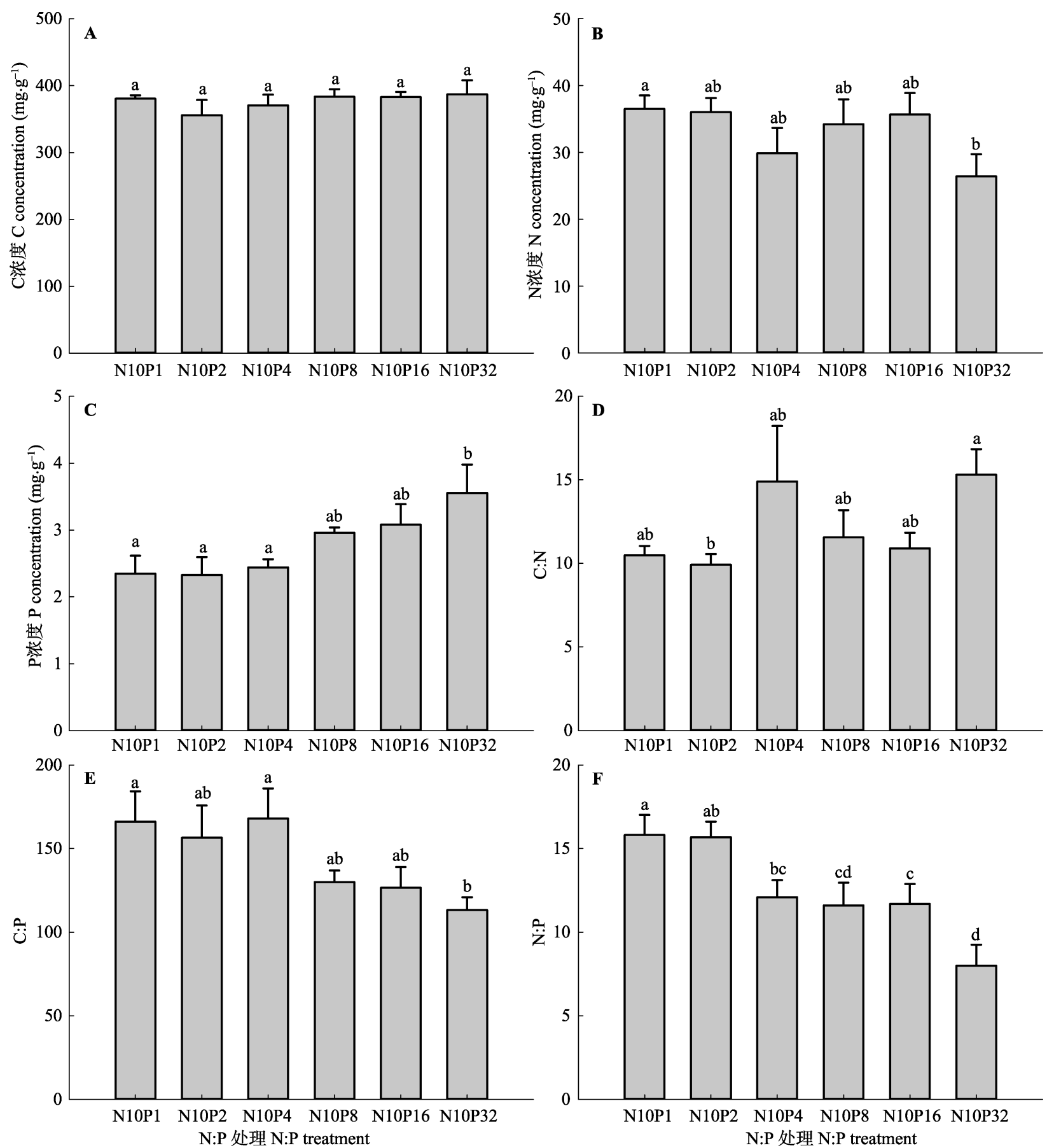

图2 不同氮 $(\mathrm{N})$ 磷 $(\mathrm{P})$ 比处理对甘草叶片碳 $(\mathrm{C}) 、 \mathrm{~N} 、 \mathrm{P}$ 及其化学计量比的影响(平均值土标准误差, $n=5)$ ) N10P1、N10P2、N10P4、 $\mathrm{N} 10 \mathrm{P} 8 、 \mathrm{~N} 10 \mathrm{P} 16$ 和N10P32代表在统一施用 $10.0 \mathrm{~g} \cdot \mathrm{m}^{-2} \cdot \mathrm{a}^{-1} \mathrm{~N}$ 的基础上, 分别施入1.0、2.0、4.0、8.0、16.0和32.0 $\mathrm{g} \cdot \mathrm{m}^{-2} \cdot \mathrm{a}^{-1}$ 的 $\mathrm{P}$ 。 不同小写字母表示N:P处理间指标差异显著 $(p<0.05)$, 相同字母表示差异不显著 $(p>0.05)$ 。

Fig. 2 Effects of nitrogen (N):phosphorus (P) level on leaf carbon (C), N, P and their stoichiometry ratios of Glycyrrhiza uralensis $($ mean $\pm S E, n=5)$. N10P1, N10P2, N10P4, N10P8, N10P16, and N10P32 represent all pots treated with $10.0 \mathrm{~g} \cdot \mathrm{m}^{-2} \cdot \mathrm{a}^{-1}$ amount of N but with different amounts of P: $1.0,2.0,4.0,8.0,16.0$, and $32.0 \mathrm{~g} \cdot \mathrm{m}^{-2} \cdot \mathrm{a}^{-1}$, respectively. Different lowercase letters indicate significant difference $(p<0.05)$ between indices within N:P levels. The same lowercase letters indicate insignificant difference $(p>0.05)$.

指标的影响无一致的规律性。平均土壤有机C含量、 全 $\mathrm{N}$ 含量、全 $\mathrm{P}$ 含量、 $\mathrm{NH}_{4}^{+}-\mathrm{N}$ 含量、 $\mathrm{NO}_{3}^{-}-\mathrm{N}$ 含量、速 效P含量、C:N、C:P和N:P分别为 $2.0 \mathrm{~g} \cdot \mathrm{kg}^{-1} 、 0.3 \mathrm{~g} \cdot \mathrm{kg}^{-1}$ 、 $0.7 \mathrm{~g} \cdot \mathrm{kg}^{-1} 、 1.6 \mathrm{mg} \cdot \mathrm{g}^{-1} 、 22.7 \mathrm{mg} \cdot \mathrm{g}^{-1} 、 103.9 \mathrm{mg} \cdot \mathrm{g}^{-1}$ 、 $7.1 、 3.7$ 和 0.5 。

\section{5 甘草叶、根系和土壤 C、N、P及其化学计量比 的相关性}

甘草生物量与土壤C:N:P化学计量学特征的相 关性较弱(表), 只有地上生物量与土壤速效 $\mathrm{P}$ 含量、 地下生物量与土壤 $\mathrm{C}: \mathrm{N}$ 存在显著的相关性。 

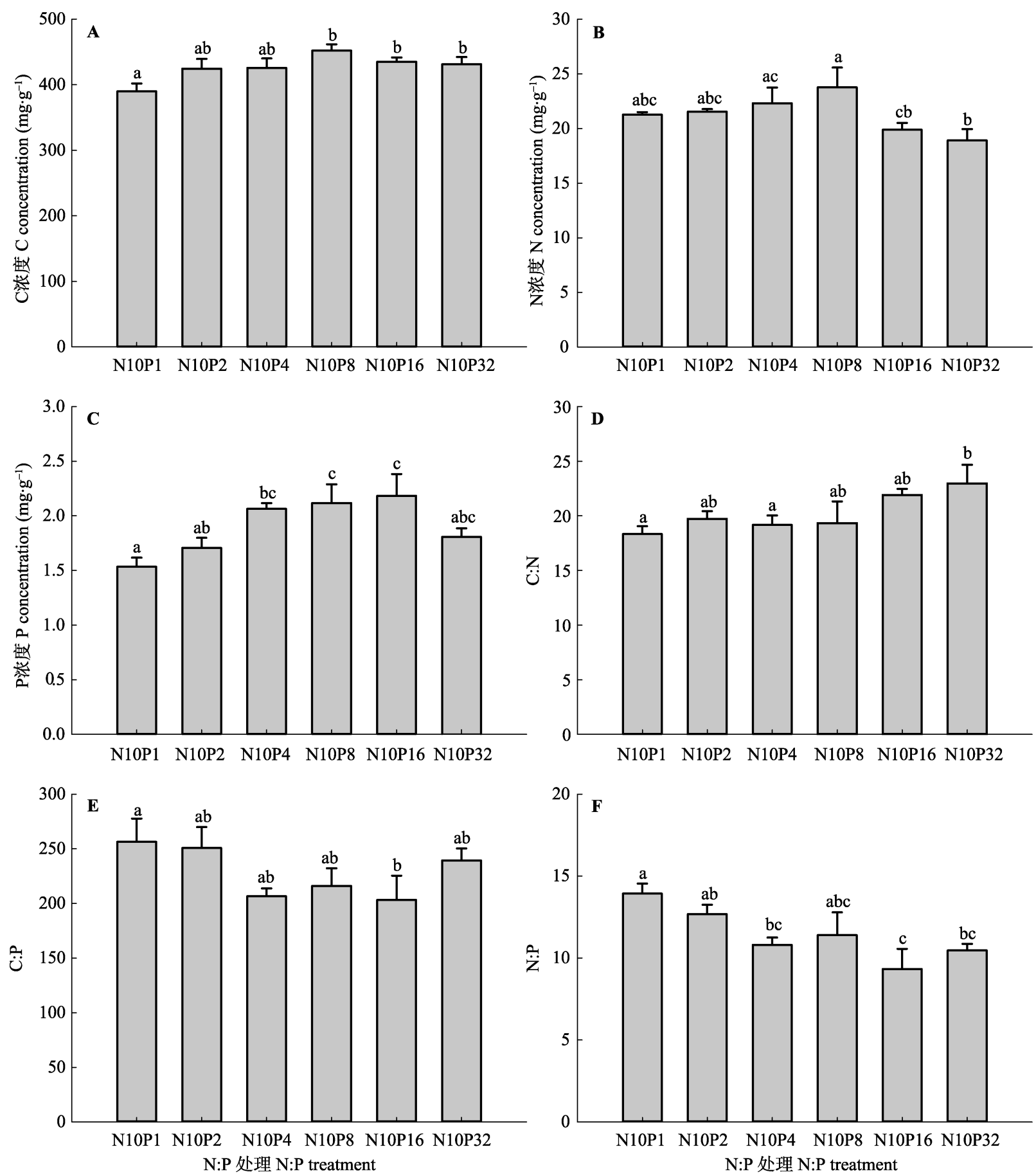

图3 不同氮 $(\mathrm{N})$ 磷 $(\mathrm{P})$ 比处理对甘草根系碳 $(\mathrm{C}) 、 \mathrm{~N} 、 \mathrm{P}$ 及其化学计量比的影响(平均值 \pm 标准误差, $n=5) \circ \mathrm{N} 10 \mathrm{P} 1 、 \mathrm{~N} 10 \mathrm{P} 2 、 \mathrm{~N} 10 \mathrm{P} 4$ 、 N10P8、N10P16和N10P32代表在统一施用 $10.0 \mathrm{~g} \cdot \mathrm{m}^{-2} \cdot \mathrm{a}^{-1} \mathrm{~N}$ 的基础上，分别施入 $1.0 、 2.0 、 4.0 、 8.0 、 16.0$ 和 $32.0 \mathrm{~g} \cdot \mathrm{m}^{-2} \cdot \mathrm{a}^{-1}$ 的 $\mathrm{P}$ 。 不同小写字母表示N:P处理间指标差异显著 $(p<0.05)$, 相同字母表示差异不显著 $(p>0.05)$ 。

Fig. 3 Effects of nitrogen (N): phosphorus (P) level on root carbon (C), N, P and their stoichiometry ratios of Glycyrrhiza uralensis (mean $\pm S E, n=5$ ). N10P1, N10P2, N10P4, N10P8, N10P16, and N10P32 represent all pots were treated with $10.0 \mathrm{~g} \cdot \mathrm{m}^{-2} \cdot \mathrm{a}^{-1}$ amount of $\mathrm{N}$ but with differing amounts of $\mathrm{P}: 1.0,2.0,4.0,8.0,16.0$, and $32.0 \mathrm{~g} \cdot \mathrm{m}^{-2} \cdot \mathrm{a}^{-1}$, respectively. Different lowercase letters indicate significant differences $(p<0.05)$ between indices within N:P levels. The same lowercase letters indicate insignificant differences $(p>$ $0.05)$.

如表2所示，叶片全C与土壤 $\mathrm{C}: \mathrm{N}: \mathrm{P}$ 化学计量学 特征无显著的相关性; 叶片全 $\mathrm{N}$ 与土壤 C:N和C:P正 相关，与全 $\mathrm{N}$ 负相关; 叶片全 $\mathrm{P}$ 与土壤全 $\mathrm{P}$ 正相关, 与 $\mathrm{C}: \mathrm{P}$ 和 $\mathrm{N}: \mathrm{P}$ 负相关; 叶片 $\mathrm{C}: \mathrm{N}$ 与土壤 $\mathrm{C}: \mathrm{N}$ 负相关; 叶
片 $\mathrm{C}: \mathrm{P}$ 与土壤 $\mathrm{C}: \mathrm{P}$ 和 $\mathrm{N}: \mathrm{P}$ 正相关，与全 $\mathrm{P}$ 负相关; 叶片 $\mathrm{N}: \mathrm{P}$ 与土壤 $\mathrm{C}: \mathrm{N} 、 \mathrm{C}: \mathrm{P}$ 和 $\mathrm{N}: \mathrm{P}$ 正相关, 与全 $\mathrm{P}$ 和速效 $\mathrm{P}$ 负 相关。

根系全 $\mathrm{C}$ 与土壤速效 $\mathrm{P}$ 正相关，与 $\mathrm{N}: \mathrm{P}$ 负相关; 
根系全 $\mathrm{N}$ 与土壤全 $\mathrm{P}$ 负相关; 根系全 $\mathrm{P}$ 和 $\mathrm{C}: \mathrm{P}$ 均与土 壤C:N:P化学计量学特征无显著的相关性; 根系C:N 与土壤全 $\mathrm{P}$ 正相关, 与 $\mathrm{C}: \mathrm{P}$ 和 $\mathrm{N}: \mathrm{P}$ 负相关; 根系 $\mathrm{N}: \mathrm{P}$ 与 土壤 $\mathrm{C}: \mathrm{P}$ 和 $\mathrm{N}: \mathrm{P}$ 正相关, 与全 $\mathrm{P}$ 负相关。

\section{6 甘草生长与 $\mathrm{C}: \mathrm{N}: \mathrm{P}$ 化学计量学特征的关系}

总体而言, 甘草生长与 $\mathrm{C}: \mathrm{N}: \mathrm{P}$ 化学计量学特征
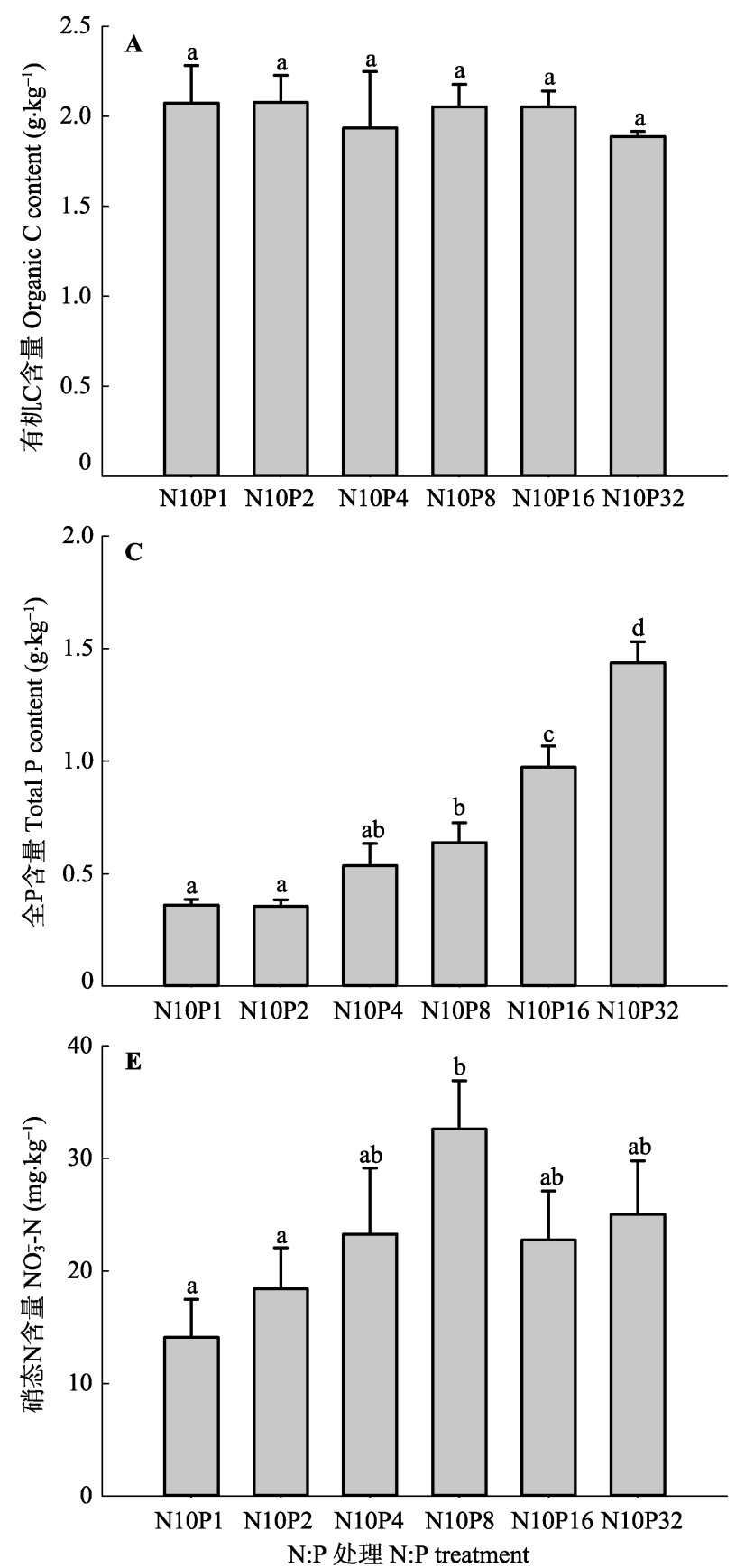

的相关性较弱(表3), 如: 地上生物量仅与土壤速 效P含量以及根系全 $\mathrm{N}$ 浓度正相关，而与其他指 标无显著的相关性; 地下生物量与土壤 C:N正相 关，与其他指标无显著的相关性; 总生物量和根 冠比均与C、N、P及其化学计量比不存在显著的 相关性。
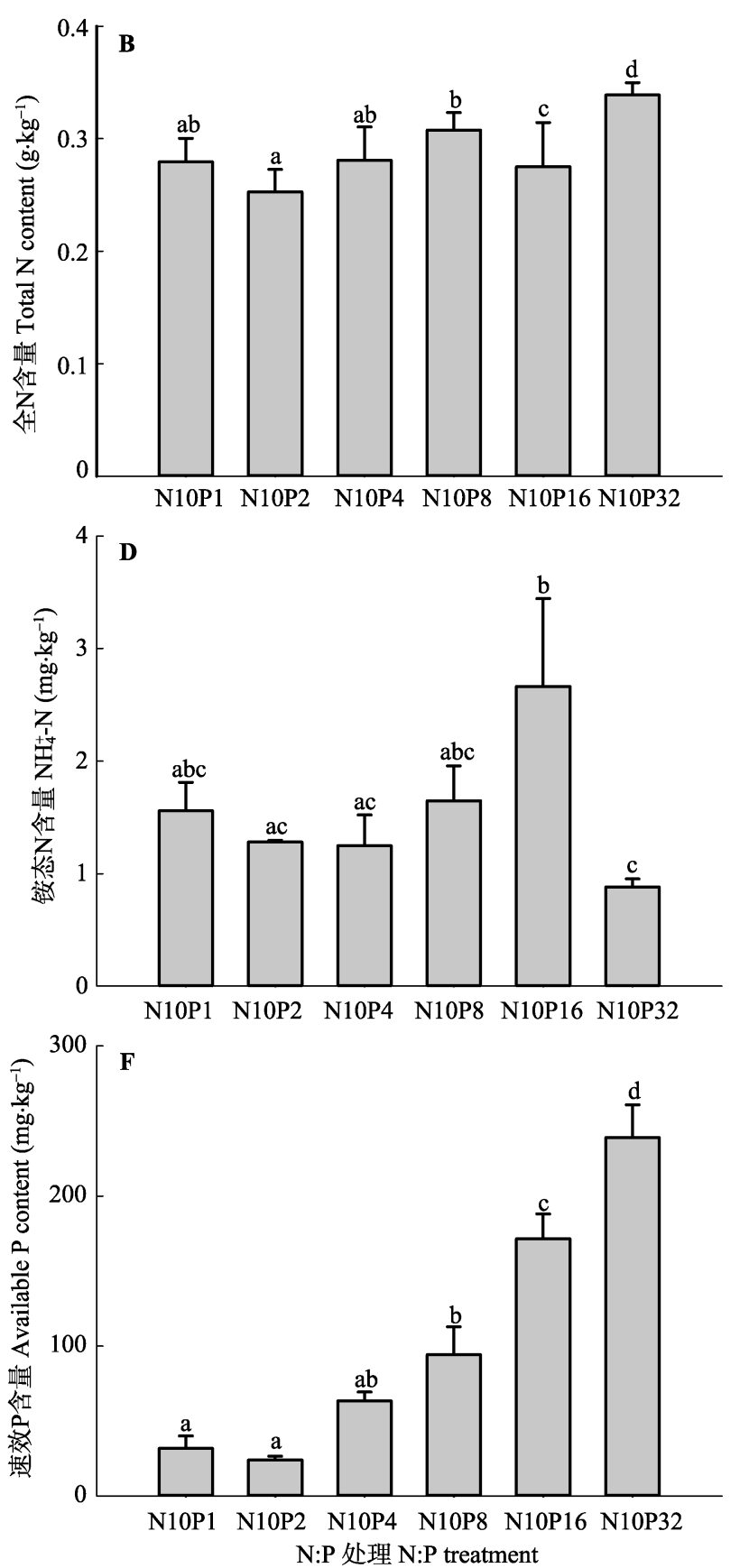

图4 不同氮 $(\mathrm{N})$ 磷 $(\mathrm{P})$ 比处理对土壤碳 $(\mathrm{C}) 、 \mathrm{~N} 、 \mathrm{P}$ 含量的影响(平均值土标准误差, $n=5)$ 。 $10 \mathrm{P} 1 、 \mathrm{~N} 10 \mathrm{P} 2 、 \mathrm{~N} 10 \mathrm{P} 4 、 \mathrm{~N} 10 \mathrm{P} 8 、 \mathrm{~N} 10 \mathrm{P} 16$ 和N10P32 代表在统一施用 $10.0 \mathrm{~g} \cdot \mathrm{m}^{-2} \cdot \mathrm{a}^{-1} \mathrm{~N}$ 的基础上, 分别施入1.0、2.0、4.0、8.0、16.0和32.0 $\mathrm{g} \cdot \mathrm{m}^{-2} \cdot \mathrm{a}^{-1}$ 的 $\mathrm{P}$ 。不同小写字母表 示N:P处理间指标差异显著 $(p<0.05)$, 相同字母表示差异不显著 $(p>0.05)$ 。

Fig. 4 Effects of nitrogen $(\mathrm{N})$ :phosphorus $(\mathrm{P})$ level on soil carbon $(\mathrm{C}), \mathrm{N}$, and P content (mean $\pm S E, n=5)$. N10P1, N10P2, N10P4, $\mathrm{N} 10 \mathrm{P} 8, \mathrm{~N} 10 \mathrm{P} 16$, and N10P32 represent all pots treated with $10.0 \mathrm{~g} \cdot \mathrm{m}^{-2} \cdot \mathrm{a}^{-1}$ amount of $\mathrm{N}$ but with different amounts of P: $1.0,2.0,4.0$, $8.0,16.0$, and $32.0 \mathrm{~g} \cdot \mathrm{m}^{-2} \cdot \mathrm{a}^{-1}$, respectively. Different lowercase letters indicate significant difference $(p<0.05)$ between indices within $\mathrm{N}: \mathrm{P}$ levels. The same lowercase letters indicate insignificant difference $(p>0.05)$. 

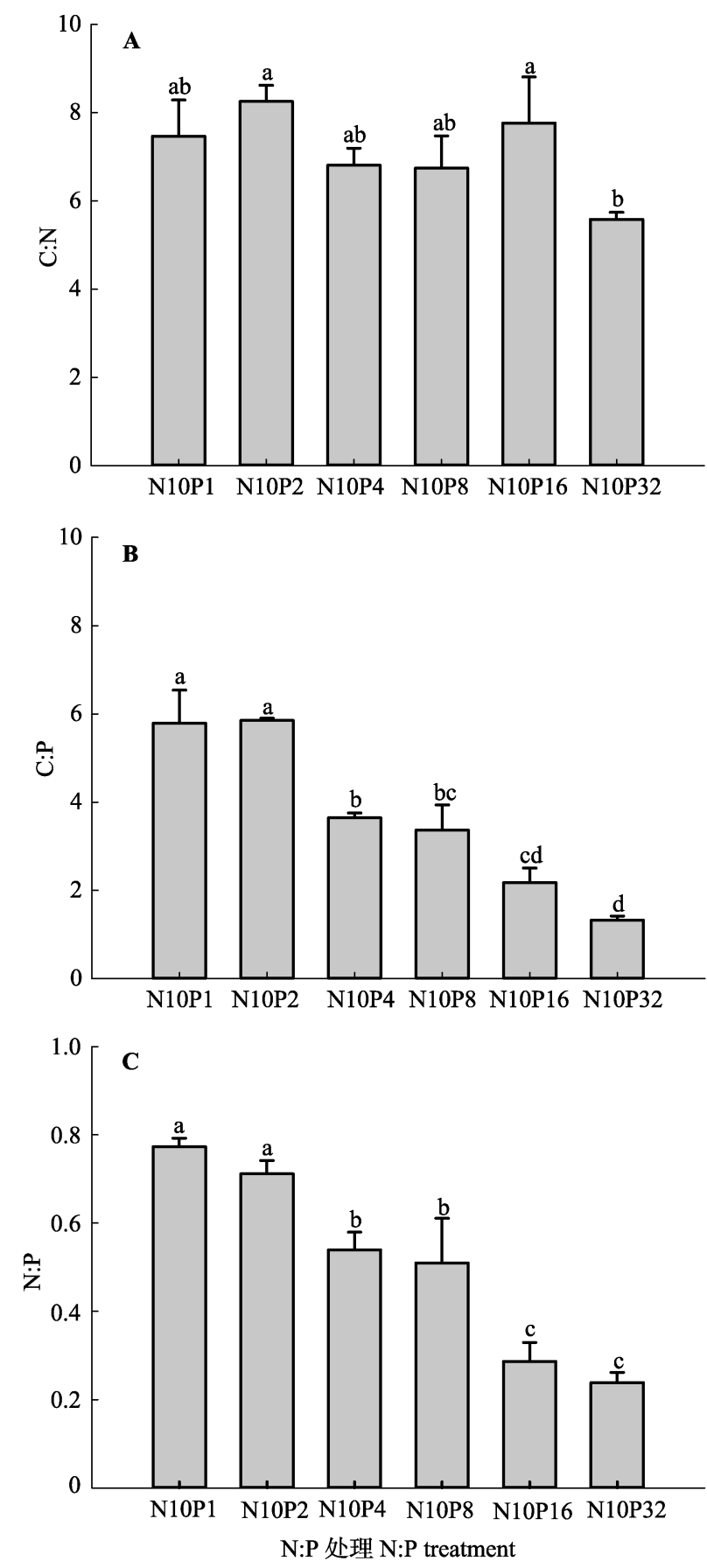

图5 不同氮 $(\mathrm{N})$ 磷 $(\mathrm{P})$ 比处理对土壤碳 $(\mathrm{C}): \mathrm{N}: \mathrm{P}$ 化学计量比的 影响(平均值土标准误差, $n=5$ )。 N10P1、N10P2、N10P4、 N10P8、N10P16和N10P32代表在统一施用 $10.0 \mathrm{~g} \cdot \mathrm{m}^{-2} \cdot \mathrm{a}^{-1} \mathrm{~N}$ 的 基础上, 分别施入 $1.0 、 2.0 、 4.0 、 8.0 、 16.0$ 和 $32.0 \mathrm{~g} \cdot \mathrm{m}^{-2} \cdot \mathrm{a}^{-1}$ 的 $\mathrm{P}$ 。不同小写字母表示N:P处理间指标差异显著 $(p<0.05)$, 相同字母表示差异不显著 $(p>0.05)$ 。

Fig. 5 Effects of nitrogen $(\mathrm{N})$ : phosphorus $(\mathrm{P})$ level on soil carbon $(\mathrm{C}): \mathrm{N}: \mathrm{P}$ stoichiometry ratio (mean $\pm S E, n=5$ ). N10P1, N10P2, N10P4, N10P8, N10P16, and N10P32 represent all pots treated with $10.0 \mathrm{~g} \cdot \mathrm{m}^{-2} \cdot \mathrm{a}^{-1}$ amount of $\mathrm{N}$ but with different amounts of P: 1.0, 2.0, 4.0, 8.0, 16.0, and $32.0 \mathrm{~g} \cdot \mathrm{m}^{-2} \cdot \mathrm{a}^{-1}$, respectively. Different lowercase letters indicate significant difference $(p<0.05)$ between indices within N:P levels. The same lowercase letters indicate insignificant difference $(p>0.05)$.

www.plant-ecology.com

\section{3 讨论}

\section{1 不同N:P处理对甘草生长的影响}

通常在 $\mathrm{N}$ 受限制的情况下，提高 $\mathrm{N}$ 的供应量、降 低P的供应量会促进植物生物量的积累 (Güsewell, 2005), 也即提高施入的N:P水平对生物量积累有促 进作用; 相反，在 $\mathrm{P}$ 受限制的情况下，降低施入的 $\mathrm{N}: \mathrm{P}$ 水平将有助于生物量的积累。对青藏高原高寒 草甸植物(杨晓霞等, 2014)和内蒙古温带草原植物 (何利元等, 2015)的研究表明, 施 $\mathrm{N}$ 显著提高了植物 地上和地下生物量，增施P对地上生物量仍有促进 作用，但对地下生物量的影响不明显。本研究中, N10P8和N10P16处理显著提高了甘草地上生物量 (图1A), 但对地下生物量影响不显著(图1B), 与高 寒草甸物种和温带草原物种反应一致。其原因可能 在于供试土壤本身全 $\mathrm{P}$ 和速效 $\mathrm{P}$ 含量都比较低，而 $10.0 \mathrm{~g} \cdot \mathrm{m}^{-2} \cdot \mathrm{a}^{-1}$ 的施 $\mathrm{N}$ 量进一步加剧了土壤 $\mathrm{P}$ 的受限 性，从而抑制了甘草的生长; 随着P施用量增加, 施 入的 $\mathrm{N}$ : $\mathrm{P}$ 水平降低, 一定程度上缓解了 $\mathrm{N}$ 添加引起的 $\mathrm{P}$ 压力, 并提高了供试土壤P的供给能力(Crews et al., 2000), 因此, 适度的 N:P处理促进了甘草地上生物 量的积累; $10.0 \mathrm{~g} \cdot \mathrm{m}^{-2} \cdot \mathrm{a}^{-1}$ 的 $\mathrm{N}$ 添加可能使甘草根系生 长达到了一个合适的水平, 因此增施P肥并不能显 著提高根系生物量。然而, 当 $\mathrm{N}: \mathrm{P}$ 处理为N10P32时, 不仅对甘草产生了 $\mathrm{P}$ 肥毒害作用，而且随着施入的 $\mathrm{N}: \mathrm{P}$ 水平降低, 甘草生长 $\mathrm{N}$ 受限性显著增加, 从而抑 制了甘草根系生长, 导致总生物量下降。在生物量 分配上, 有研究发现当植物生长主要受 $N$ 限制时, $N$ 添加更倾向于降低根冠比; 而当植物生长主要受 $\mathrm{P}$ 限制时, P添加更倾向于提高根冠比(Güsewell, 2005; 刘洋等, 2013)。我们的研究显示, 在统一施用 $10.0 \mathrm{~g} \cdot \mathrm{m}^{-2} \cdot \mathrm{a}^{-1} \mathrm{~N}$ 的基础上随着P施用量增加, 甘草 根冠比呈先降低后增加的趋势, 与Güsewell (2005) 和刘洋等(2013)的研究结果略有不同。总体而言, 甘草根冠比在几个 $\mathrm{N}: \mathrm{P}$ 处理间无显著差异, 表明 与单施 $\mathrm{N}$ 或 $\mathrm{P}$ 相比较, $\mathrm{N}$ 和 $\mathrm{P}$ 共同添加使植物生物量 在地上和地下间的分配策略变得更加复杂。

\section{2 不同 N:P处理对甘草和土壤 C:N:P化学计量学 特征的影响}

对全球尺度土壤数据的综合分析表明, 有机 C 含量的变化范围为1.108 $0-39.0830 \mathrm{~mol} \cdot \mathrm{kg}^{-1}$, 全N 含量则从 $21.0 \mathrm{mmol} \cdot \mathrm{kg}^{-1}$ 变化到超过 $1.3000 \mathrm{~mol} \cdot \mathrm{kg}^{-1}$ (Cleveland \& Liptzin, 2007)。基于2 384个中国0-10 cm 
表2 甘草与土壤碳 $(\mathrm{C})$ 、氮 $(\mathrm{N})$ 、磷 $(\mathrm{P})$ 含量及其化学计量比间的相关系数

Table 2 Correlation coefficients between carbon $(\mathrm{C})$, nitrogen $(\mathrm{N})$, phosphorus $(\mathrm{P})$ and their stoichiometry ratios in Glycyrrhiza uralensis and in soils

\begin{tabular}{|c|c|c|c|c|c|c|c|}
\hline $\begin{array}{l}\text { 指标 } \\
\text { Index }\end{array}$ & $\begin{array}{c}\text { 土壤有机C } \\
\text { Soil organic } \mathrm{C} \\
\left(\mathrm{g} \cdot \mathrm{kg}^{-1}\right)\end{array}$ & $\begin{array}{c}\text { 土壤全N } \\
\text { Soil total N } \\
\left(\mathrm{g} \cdot \mathrm{kg}^{-1}\right)\end{array}$ & $\begin{array}{c}\text { 土壤全P } \\
\text { Soil total P } \\
\left(\mathrm{g} \cdot \mathrm{kg}^{-1}\right)\end{array}$ & $\begin{array}{c}\text { 土壤速效 } \mathrm{P} \\
\text { Soil available } \mathrm{P} \\
\left(\mathrm{mg} \cdot \mathrm{kg}^{-1}\right)\end{array}$ & $\begin{array}{l}\text { 土壤 C: } \mathrm{N} \\
\mathrm{C}_{\text {soil }}: \mathrm{N}_{\text {soil }}\end{array}$ & $\begin{array}{l}\text { 土壤C:P } \\
\mathrm{C}_{\text {soil }}: \mathrm{P}_{\text {soil }}\end{array}$ & $\begin{array}{l}\text { 土壤 } \mathrm{N}: \mathrm{P} \\
\mathrm{N}_{\text {soil }}: \mathrm{P}_{\text {soil }}\end{array}$ \\
\hline 地上生物量 Aboveground biomass $\left(\mathrm{g} \cdot \mathrm{plant}^{-1}\right)$ & ns & ns & ns & $0.51^{*}$ & ns & ns & 0.05 \\
\hline 地下生物量 Belowground biomass (g·plant ${ }^{-1}$ ) & ns & ns & ns & ns & $0.50^{*}$ & ns & ns \\
\hline 叶片全C Leaf total C $\left(\mathrm{mg} \cdot \mathrm{g}^{-1}\right)$ & ns & ns & ns & ns & ns & ns & ns \\
\hline 叶片全N Leaf total N $\left(\mathrm{mg} \cdot \mathrm{g}^{-1}\right)$ & ns & $-0.56^{*}$ & ns & ns & $0.69^{* *}$ & $0.50^{*}$ & ns \\
\hline 叶片全P Leaf total P $\left(\mathrm{mg} \cdot \mathrm{g}^{-1}\right)$ & ns & ns & $0.77^{* *}$ & ns & ns & $-0.70^{* *}$ & $-0.75^{* *}$ \\
\hline 叶片C: $\mathrm{N} \mathrm{C}_{\text {leaf }} \mathrm{N}_{\text {leaf }}$ & ns & ns & $\mathrm{ns}$ & ns & $-0.56^{*}$ & ns & ns \\
\hline 叶片C:P C & ns & ns & $-0.63^{* *}$ & ns & ns & $0.58^{*}$ & $0.64^{* *}$ \\
\hline 叶片 $\mathrm{N}: \mathrm{P} \mathrm{N}_{\text {leaf }}: \mathrm{P}_{\text {leaf }}$ & ns & ns & $-0.80^{* *}$ & $-0.49^{*}$ & $0.57^{*}$ & $0.85^{* *}$ & $0.79^{* *}$ \\
\hline 根系全C Root total C $\left(\mathrm{mg} \cdot \mathrm{g}^{-1}\right)$ & $\mathrm{ns}$ & ns & $\mathrm{ns}$ & $0.62^{* *}$ & ns & ns & $-0.53^{*}$ \\
\hline 根系全N Root total N $\left(\mathrm{mg} \cdot \mathrm{g}^{-1}\right)$ & ns & $\mathrm{ns}$ & $-0.50^{*}$ & ns & ns & ns & ns \\
\hline 根系全P Root total P $\left(\mathrm{mg} \cdot \mathrm{g}^{-1}\right)$ & ns & ns & ns & ns & $\mathrm{ns}$ & $\mathrm{ns}$ & ns \\
\hline 根系C:N C & ns & ns & $0.66^{* *}$ & ns & ns & $-0.58^{*}$ & $-0.70^{* *}$ \\
\hline 根系C:P C & ns & ns & ns & ns & ns & ns & ns \\
\hline 根系N:P N $\mathrm{N}_{\text {root }}: \mathrm{P}_{\text {root }}$ & ns & ns & $-0.57^{*}$ & ns & ns & $0.65^{* *}$ & $0.67^{* *}$ \\
\hline
\end{tabular}

ns代表显著性水平大于 0.05 。 $*$ 和**分别代表显著性水平小于 0.05 和 0.01 。

ns indicates that correlation is insignificant at 0.05 level. * and ** indicate that correlations are significant at the 0.05 and 0.01 levels, respectively.

表3 碳 $(\mathrm{C})$ :氮 $(\mathrm{N})$ : 磷 $(\mathrm{P})$ 化学计量学特征与甘草生物量和根冠比的相关系数

Table 3 Correlation coefficients between carbon (C):nitrogen (N):phosphorus (P) ecological stoichiometry and the biomass or root/shoot ratio of Glycyrrhiza uralensis

\begin{tabular}{|c|c|c|c|c|}
\hline $\begin{array}{l}\text { 指标 } \\
\text { Index }\end{array}$ & $\begin{array}{c}\text { 地上生物量 } \\
\text { Aboveground biomass } \\
\left(\mathrm{g} \cdot \text { plant }^{-1}\right)\end{array}$ & $\begin{array}{c}\text { 地下生物量 } \\
\text { Belowground biomass } \\
\left(\mathrm{g} \cdot \text { plant }^{-1}\right)\end{array}$ & $\begin{array}{l}\text { 总生物量 } \\
\text { Total biomass } \\
\left(\mathrm{g} \cdot \text { plant }^{-1}\right)\end{array}$ & $\begin{array}{c}\text { 根冠比 } \\
\text { Rooot/shoot ratio }\end{array}$ \\
\hline 土壤有机C Soil organic C $\left(\mathrm{g} \cdot \mathrm{kg}^{-1}\right)$ & 0.18 & 0.35 & 0.32 & -0.37 \\
\hline 土壤全N Soil total N $\left(\mathrm{g} \cdot \mathrm{kg}^{-1}\right)$ & -0.01 & -0.33 & -0.23 & -0.21 \\
\hline 土壤全P Soil total P $\left(\mathrm{g} \cdot \mathrm{kg}^{-1}\right)$ & -0.27 & -0.39 & -0.39 & 0.01 \\
\hline 土壤速效P Soil available P $\left(\mathrm{mg} \cdot \mathrm{kg}^{-1}\right)$ & $0.51^{*}$ & 0.18 & 0.35 & -0.05 \\
\hline 土壤 $\mathrm{C}: \mathrm{N} \mathrm{C}_{\text {soil }}: \mathrm{N}_{\text {soil }}$ & 0.12 & $0.50^{*}$ & 0.40 & 0.04 \\
\hline 土壤 $\mathrm{C}: \mathrm{P} \mathrm{C}_{\text {soil }}: \mathrm{P}_{\text {soil }}$ & -0.00 & 0.19 & 0.13 & 0.18 \\
\hline 土壤 $\mathrm{N}: \mathrm{P} \mathrm{N}_{\text {soil }}: \mathrm{P}_{\text {soil }}$ & 0.05 & 0.07 & 0.07 & 0.13 \\
\hline 叶片全C Leaf total C $\left(\mathrm{mg} \cdot \mathrm{g}^{-1}\right)$ & 0.07 & -0.08 & -0.03 & -0.33 \\
\hline 叶片全 $\mathrm{N}$ Leaf total $\mathrm{N}\left(\mathrm{mg} \cdot \mathrm{g}^{-1}\right)$ & 0.25 & 0.35 & 0.35 & -0.27 \\
\hline 叶片全P Leaf total P $\left(\mathrm{mg} \cdot \mathrm{g}^{-1}\right)$ & -0.07 & -0.31 & -0.25 & -0.25 \\
\hline 叶片C: $\mathrm{N} \mathrm{C}_{\text {leaf }}: \mathrm{N}_{\text {leaf }}$ & -0.18 & -0.21 & -0.22 & 0.27 \\
\hline 叶片C:P C leaf: $\mathrm{P}_{\text {leaf }}$ & 0.02 & 0.22 & 0.16 & 0.41 \\
\hline 叶片 $\mathrm{N}: \mathrm{P} \mathrm{N}_{\text {leaf }}: \mathrm{P}_{\text {leaf }}$ & 0.07 & 0.29 & 0.23 & 0.15 \\
\hline 根系全C Root total C $\left(\mathrm{mg} \cdot \mathrm{g}^{-1}\right)$ & 0.39 & 0.39 & 0.44 & -0.68 \\
\hline 根系全N Root total N $\left(\mathrm{mg} \cdot \mathrm{g}^{-1}\right)$ & $0.49^{*}$ & 0.21 & 0.36 & -0.58 \\
\hline 根系全P Root total P $\left(\mathrm{mg} \cdot \mathrm{g}^{-1}\right)$ & 0.43 & 0.19 & 0.32 & -0.55 \\
\hline 根系C:N C $\mathrm{Crot}_{\text {rot: }} \mathrm{N}_{\text {root }}$ & -0.22 & -0.03 & -0.12 & 0.10 \\
\hline 根系C:P C & -0.29 & -0.05 & -0.17 & 0.39 \\
\hline 根系N:P N root $_{\text {root }}$ & -0.07 & -0.04 & -0.06 & 0.18 \\
\hline
\end{tabular}

*,p<0.05。

土壤数据, Tian等(2010)发现平均土壤有机C、全N和 全P含量分别为 $2047.0 、 134.0$ 和 $25.0 \mathrm{mmol} \cdot \mathrm{kg}^{-1}$ 。本 研究中, N:P处理为 $\mathrm{N} 10 \mathrm{P} 1\left(\mathrm{P}\right.$ 添加量为 $1.0 \mathrm{~g} \cdot \mathrm{m}^{-2} \cdot \mathrm{a}^{-1}$ ) 时, 土壤有机 $\mathrm{C} 、$ 全 $\mathrm{N}$ 和全 $\mathrm{P}$ 含量分别为 $2.1 、 0.3$ 和 $0.4 \mathrm{~g} \cdot \mathrm{kg}^{-1}$ (换算后的摩尔浓度分别为175.0、21.0和
$13.0 \mathrm{mmol} \cdot \mathrm{kg}^{-1}$ ), 明显低于全球和全国水平, 表明 连续两年高 $\mathrm{N}: \mathrm{P}$ 处理后(N10P32), 土壤有机C和养分 依然很贫乏, 限制了甘草生长和养分摄取。施用 $\mathrm{P}$ 肥逐渐改善了土壤中 $\mathrm{P}$ 的可利用性、缓解了 $\mathrm{P}$ 受限性, 因此土壤全 $\mathrm{P}$ 和速效 $\mathrm{P}$ 含量显著增加、而 $\mathrm{C}: \mathrm{P}$ 和 $\mathrm{N}: \mathrm{P}$ 显 
著降低(图5B、图5C)。受土壤 $\mathrm{P}$ 供给水平变化特点 的影响, 叶片 $\mathrm{P}$ 浓度表现出逐渐增加的趋势, 并在 低、中 $\mathrm{N}: \mathrm{P}$ 水平下表现显著, 表明中、高P添加使叶 片P摄取增强, 与以往研究结果(Crous et al., 2008; Mayor et al., 2014)相似。由于供试土壤属于轻度碱 化土壤, 土壤中的 $\mathrm{P}$ 易与游离态 $\mathrm{CaCO}_{3}$ 结合形成难 溶性的磷酸钙盐(Cross \& Schlesinger, 2001), 同时, $10.0 \mathrm{~g} \cdot \mathrm{m}^{-2} \cdot \mathrm{a}^{-1}$ 的 $\mathrm{N}$ 添加加剧了供试土壤 $\mathrm{P}$ 受限性, 少 量 $\mathrm{P}$ 添加可能不足以消除叶片 $\mathrm{P}$ 限制(Fritz et al., 2012), 因而此时叶片 $\mathrm{P}$ 浓度的变化幅度较小(图2C)。 高 $\mathrm{N}: \mathrm{P}$ 施入水平下叶片 $\mathrm{N}$ 浓度的变化幅度也很小, $\mathrm{N} 10 \mathrm{P} 32$ 的 N:P施入水平使叶片 $\mathrm{N}$ 浓度下降至 $26.4 \mathrm{mg} \cdot \mathrm{g}^{-1}$, 表明低 $\mathrm{N}: \mathrm{P}$ 施入水平限制了甘草 $\mathrm{N}$ 摄取, 导致甘草叶片 $\mathrm{N}$ 保持能力增强。关于植物根系 $\mathrm{C}: \mathrm{N}: \mathrm{P}$ 化学计量学特征, 有研究表明少量 $\mathrm{N}$ 和 $\mathrm{P}$ 共施提高 了麦冬(Ophiopogon japonicus)根部N浓度、P浓度和 $\mathrm{N}: \mathrm{P}$ (陈伏生等, 2007)。本研究发现较高水平的 N:P 施入也提高了甘草根系 $\mathrm{N}$ 和P浓度, 但降低了 $\mathrm{C}: \mathrm{P}$ 和 $\mathrm{N}: \mathrm{P}$ (图3 E、图3F), 说明少量P添加促进了根系对 $\mathrm{N}$ 和 $\mathrm{P}$ 的共同吸收, 但由于根系对 $\mathrm{P}$ 吸收的速度快于对 $\mathrm{N}$ 的吸收, 从而导致根系C:P和N:P下降。

\section{3 甘草和土壤 C:N:P化学计量学特征间的差异和 联系}

植被-土壤系统C、N、P循环是在植物和土壤之 间相互转换的。植物 $\mathrm{C}: \mathrm{N}: \mathrm{P}$ 化学计量比不仅反映了植 物对 $\mathrm{N}$ 和 $\mathrm{P}$ 的利用效率, 而且在一定程度上决定着 调落物分解质量, 间接反映了土壤中 $\mathrm{N}$ 和 $\mathrm{P}$ 的供应。 反过来, 土壤 $\mathrm{C}: \mathrm{N}$ 和 $\mathrm{C}: \mathrm{P}$ 的高低又决定了微生物活动 的变化趋势(固持或矿化)和植物获得有效 $\mathrm{N}$ 和 $\mathrm{P}$ 的情 况。本研究中, 甘草叶片和根系C:N:P化学计量学特 征均与土壤 $\mathrm{C}: \mathrm{N}: \mathrm{P}$ 化学计量学特征存在不同程度的 相关性(表2), 表明土壤C、N、P及其计量关系的改 变会直接作用于植物。由于植物叶片和根系在养分 储存及其功能性上的差异(刘超等, 2012), 甘草叶片 和根系化学计量特征的变化对 $\mathrm{N}$ 和 $\mathrm{P}$ 输入的反应差 异显著, 且根系N浓度、P浓度、C:N、C:P和N:P的 变化幅度较小、内稳性较高, 与其他研究结果 (赵 亚芳等, 2014; 石贤萌等, 2015)相似。结合甘草叶 片、根系和土壤三个库间 C:N:P化学计量学特征的差 异和联系, 以上结果证实全球气候变化背景下, 土 壤和植物叶片 $\mathrm{C} 、 \mathrm{~N} 、 \mathrm{P}$ 平衡关系将趋于解耦
(Delgado-Baquerizo et al., 2013; Yang et al., 2014; Yuan et al., 2015), 但植物根系C:N:P化学计量关系 则相对不容易受环境变化的影响。

土壤和叶片 C:N:P化学计量比在一定程度上可 以指示植物体 $\mathrm{N}$ 和 $\mathrm{P}$ 受限类型, 且与 $\mathrm{N}$ 和 $\mathrm{P}$ 的利用效 率存在关联(Tian et al., 2010; Huang et al., 2016), 因 此植物和土壤 $\mathrm{C}: \mathrm{N}: \mathrm{P}$ 化学计量比的变化可能会直接 改变植物叶片 $\mathrm{N}$ 和 $\mathrm{P}$ 摄取等过程, 进而对植物生长 产生影响。本研究中, 甘草叶片 $\mathrm{P}$ 浓度与土壤 $\mathrm{P}$ 浓度 以及根系 $\mathrm{C}: \mathrm{N}$ 正相关、与土壤 $\mathrm{C}: \mathrm{P}$ 和 $\mathrm{N}: \mathrm{P}$ 负相关(表2), 表明随着 $\mathrm{N}: \mathrm{P}$ 施入水平降低, 土壤中 $\mathrm{P}$ 的供给水平提 高, 土壤 $\mathrm{C}: \mathrm{P}$ 和 $\mathrm{N}: \mathrm{P}$ 下降, 因而土壤 $\mathrm{P}$ 受限性降低, 可 供植物吸收利用的 $\mathrm{P}$ 增多, 叶片 $\mathrm{P}$ 保持能力随之降 低。对于叶片 $\mathrm{N}$ 浓度, 随着 $\mathrm{N}: \mathrm{P}$ 施入水平降低, 虽然 土壤全 $\mathrm{N}$ 含量保持相对较高的水平, 但持续升高的 施 $\mathrm{P}$ 量对甘草根系生长产生了毒害作用, 间接降低 了叶片 $\mathrm{N}$ 吸收能力, 因此叶片 $\mathrm{N}$ 浓度表现出与土壤 全 $\mathrm{N}$ 含量负相关, 而和土壤 $\mathrm{C}: \mathrm{N}$ 和 C:P正相关, 与郭 子武等(2012)的研究结果类似。可能受甘草固 N特性 以及其叶片 $\mathrm{N}$ 和P浓度非一致性反应等因素的综合 影响, 甘草生物量与土壤 $\mathrm{C}: \mathrm{N}: \mathrm{P}$ 化学计量学特征的相 关性较弱, 仅地上生物量与土壤速效 $\mathrm{P}$ 含量正相关, 地下生物量与土壤 C:N正相关(表2)。

在森林和酸性泥炭沼泽等 $\mathrm{N}: \mathrm{P}$ 较高的生态系统, 研究人员已证实长期 $\mathrm{N}$ 沉降增加会导致系统 $\mathrm{P}$ 限制 增加(Phuyal et al., 2008; Zhu et al., 2013)。对宁夏荒 漠草原而言, 尽管已监测到的 $\mathrm{N}$ 沉降量低于其他生 态系统(Liu et al., 2013), 但是其本身 $\mathrm{N}$ 沉降临界负 荷低, 因此可能对长期低剂量N沉降增加比较敏感 (段雷等, 2002)。本研究结果表明, 随着 N:P施入水平 降低, 土壤 $\mathrm{C}: \mathrm{P}$ 和 $\mathrm{N}: \mathrm{P}$ 呈降低趋势, 从而缓解了系统 $\mathrm{P}$ 限制、增强了叶片 $\mathrm{P}$ 摄取、提高了叶片和根系 $\mathrm{C}: \mathrm{P}$ 和 $\mathrm{N}: \mathrm{P}$, 促进了甘草生长。因此, 适当的人为 $\mathrm{P}$ 添加 可通过调节土壤和植物叶片 $\mathrm{C}: \mathrm{N}: \mathrm{P}$ 化学计量学特征, 缓解土壤和植物间 $\mathrm{P}$ 的供需压力, 并削弱长期大气 $\mathrm{N}$ 沉降增加对群落结构的负面影响, 研究结果可为 全球变化背景下荒漠草原生态系统的适应性管理提 供科学依据。考虑到甘草自身的固 $\mathrm{N}$ 特性, 今后进行 田间试验验证时, 有必要通过长期的野外模拟试验 在不同功能群物种间进行比较和探讨。

基金项目 国家自然科学基金(31360111和31000215)。 


\section{参考文献}

Bao SD (2000). Soil and Agricultural Chemistry Analysis. 3rd ed. China Agriculture Press, Beijing. (in Chinese). [鲍士旦 (2000). 土壤农化分析. 第三版. 中国农业出版社, 北京.]

Bobbink R, Hicks K, Galloway J, Spranger T, Alkemade R, Ashmore M, Bustamante M, Cinderby S, Davidson E, Dentener F, Emmett B, Erisman JW, Fenn M, Gilliam F, Nordin A, Pardo L, de Vries W (2010). Global assessment of nitrogen deposition effects on terrestrial plant diversity: A synthesis. Ecological Applications, 20, 30-59.

Chen FS, Hu XF, Ge G (2007). Leaf N:P stoichiometry and nutrient resorption efficiency of Ophiopogon japonicus in Nanchang City. Acta Prataculturae Sinica, 16(4), 47-54. (in Chinese with English abstract) [陈伏生, 胡小飞, 葛刚 (2007). 城市地被植物麦冬叶片氮磷和养分再吸收效率. 草业学报, 16(4), 47-54.]

Clark CM, Tilman D (2008). Loss of plant species after chronic low-level nitrogen deposition to prairie grasslands. Nature, 451, 712-715.

Cleveland CC, Liptzin D (2007). C:N:P stoichiometry in soil: Is there a "Redfield ratio" for the microbial biomass? Biogeochemistry, 85, 235-252.

Crews TE, Farrington H, Vitousek PM (2000). Changes in a symbiotic, heterotrophic nitrogen fixation on leaf litter of Metrosideros polymorpha with long-term ecosystem development in Hawaii. Ecosystems, 3, 386-395.

Cross AF, Schlesinger WH (2001). Biological and geochemical controls on phosphorus fractions in semiarid soils. Biogeochemistry, 52, 155-172.

Crous JW, Morris AR, Scholes MC (2008). Growth and foliar nutrient response to recent applications of phosphorus $(\mathrm{P})$ and potassium $(\mathrm{K})$ and to residual $\mathrm{P}$ and $\mathrm{K}$ fertiliser applied to the previous rotation of Pinus patula at Usutu, Swaziland. Forest Ecology Management, 256, 712-721.

Delgado-Baquerizo M, Maestre FT, Gallardol A, Bowker MA, Wallenstein MD, Quero JL, Ochoa V, Gozalo B, GarcíaGómez M, Soliveres S, García-Palacios P, Berdugo M, Valencia E, Escolar C, Arredondo T, Barraza-Zepeda C, Bran D, Carreira JA, Chaieb M, Conceicão AA, Derak M, Eldridge DJ, Escudero A, Espinosa CI, Gaitán J, Gatica MG, Gómez-González S, Guzman E, Gutiérrez JR, Florentino A, Hepper E, Hernández RM, Huber-Sannwald E, Jankju M, Liu J, Mau RL, Miriti M, Monerris J, Naseri K, Noumi Z, Polo V, Prina A, Pucheta E, Ramírez E, Ramírez-Collantes DA, Romão R, Tighe M, Torres D, Torres-Díaz C, Ungar ED, Val J, Wamiti W, Wang D, Zaady E (2013). Decoupling of soil nutrient cycles as a function of aridity in global drylands. Nature, 502, 672-676.

Duan L, Hao JM, Xie SD, Zhou ZP (2002). Estimating critical loads of sulfur and nitrogen for Chinese soils by steady state method. Journal of Environmental Science, 23(2),
7-12. (in Chinese with English abstract). [段雷, 郝吉明, 谢绍东, 周中平 (2002). 用稳态法确定中国土壤的硫沉 降和氮沉降临界负荷. 环境科学, 23(2), 7-12.]

Fritz C, van Dijk G, Smolders AJP, Pancotto VA, Elzenga TJTM, Roelofs JGM, Grootjans AP (2012). Nutrient additions in pristine Patagonian Sphagnum bog vegetation: Can phosphorus addition alleviate (the effects of) increased nitrogen loads. Plant Biology, 14, 491-499.

Guo ZW, Chen SL, Yang QP, Li YC (2012). Responses of N and $\mathrm{P}$ stoichiometry on mulching management in the stand of Phyllostachys praecox. Acta Ecologica Sinica, 32, 6361-6368. (in Chinese with English abstract) [郭子武, 陈双林, 杨清平, 李迎春 (2012). 雷竹林土壤和叶片N、 $\mathrm{P}$ 化学计量特征对林地覆盖的响应. 生态学报, 32, 6361-6368.]

Güsewell S (2005). Responses of wetland graminoids to the relative supply of nitrogen and phosphorus. Plant Ecology, 176, 35-55.

He LY, Hu ZM, Guo Q, Li SG, Bai WM, Li LH (2015). Influence of nitrogen and phosphorus addition on the aboveground biomass in Inner Mongolia temperate steppe, China. Chinese Journal of Applied Ecology, 26, 2291-2297. (in Chinese with English abstract) [何利元, 胡中民, 郭 群, 李胜功, 白文明, 李凌浩 (2015). 氮磷添加对内蒙 古温带草地地上生物量的影响. 应用生态学报, 26, 2291-2297.]

Huang JY, Yu HL (2016). Responses of growth of four desert species to different $\mathrm{N}$ addition levels. Chinese Journal of Plant Ecology, 40, 165-176. (in Chinese with English abstract) [黄菊荣, 余海龙 (2016). 4 个荒漠草原物种的生 长对不同氮添加水平的响应. 植物生态学报, 40, 165-176.]

Huang JY, Yu HL, Lin H, Zhang Y, Searle EB, Yuan ZY (2016). Phosphorus amendment mitigates nitrogen addition-induced phosphorus limitation in two plant species in a desert steppe, China. Plant and Soil, 399, 221-232.

IPCC (Intergovernmental Panel on Climate Change) (2013). Climate Change 2013: The Physical Science Basis. Cambridge University Press, Cambridge, UK.

Jones AG, Power SA (2012). Field-scale evaluation of effects of nitrogen deposition on the functioning of heathland ecosystems. Journal of Ecology, 100, 331-342.

Li XB, Chen L, LI GQ, An H (2013). Influence of enclosure on Glyeyrrhiza uralensis community and distribution pattern in arid and semi-arid areas. Acta Ecologica Sinica, 33, 3995-4001. (in Chinese with English abstract) [李学斌, 陈林, 李国旗, 安慧 (2013). 干旱半干旱地区围栏封育 对甘草群落特征及其分布格局的影响. 生态学报, 33 , 3995-4001.]

Li XB, Zhao ZF, Chen L, An H, Li GQ, Liu BR (2012). The status and countermeasures of development on licorices industry of Ningxia. Ecological Economy, 12, 132-135. (in Chinese with English abstract) [李学斌, 赵志锋, 陈 
林, 安慧, 李国旗, 刘秉儒 (2012). 宁夏甘草产业发展 现状及对策研究. 生态经济, 12, 132-135.]

Liu C, Wang Y, Wang N, Wang GX (2012). Advances research in plant nitrogen, phosphorus and their stoichiometry in terrestrial ecosystems: A review. Chinese Journal of Plant Ecology, 36, 1205-1216. (in Chinese with English abstract) [刘超, 王洋, 王楠, 王根轩 (2012). 陆地生态系 统植被氮磷化学计量研究进展. 植物生态学报, 36, 1205-1216.]

Liu P, Huang JH, Sun OJX (2010). Litter decomposition and nutrient release as affected by soil nitrogen availability and litter quality in a semiarid grassland ecosystem. Oecologia, $162,771-780$.

Liu XJ, Zhang Y, Han WX, Tang AH, Shen JL, Cui ZL, Vitousek P, Erisman JW, Goulding K, Christie P, Fangmeier A, Zhang FS (2013). Enhanced nitrogen deposition over China. Nature, 494, 459-462.

Liu Y, Zhang J, Chen YM, Chen L, Liu Q (2013). Effect of nitrogen and phosphorus fertilization on biomass allocation and C:N:P stoichiometric characteristics of Eucalyptus grandis seedlings. Chinese Journal of Plant Ecology, 37, 933-941. (in Chinese with English abstract) [刘洋, 张 健, 陈亚梅, 陈磊, 刘强 (2013). 氮磷添加对巨桉幼苗 生物量分配和 C:N:P化学计量特征的影响. 植物生态学 报, 37, 933-941.]

Mayor JR, Wright SJ, Turner BL (2014). Species-specific responses of foliar nutrients to long-term nitrogen and phosphorus additions in a lowland tropical forest. Journal of Ecology, 102, 36-44.

Naples BK, Fisk MC (2010). Belowground insights into nutrient limitation in northern hardwood forests. Biogeochemistry, 97, 109-121.

Phoenix GK, Booth RE, Leake JR, Read DJ, Grime JP, Lee JA (2004). Simulated pollutant nitrogen deposition increases $P$ demand and enhances root-surface phosphatase activities of three plant functional types in a calcareous grassland. New Phytologist, 161, 279-289.

Phuyal M, Artz RRE, Sheppard L, Leith ID, Johnson D (2008). Long-term nitrogen deposition increases phosphorus limitation of bryophytes in an Ombrotrophic Bog. Plant Ecology, 196, 111-121.

Shi XM, Qi JH, Song L, Liu WY, Huang JB, Li S, Lu HZ, Chen X (2015). C, N and P stoichiometry of two dominant seedlings and their responses to nitrogen additions in the montane moist evergreen broad-leaved forest in Ailao Mountains, Yunnan. Chinese Journal of Plant Ecology, 39, 962-970. (in Chinese with English abstract) [石贤萌, 杞
金华，宋亮，刘文耀，黄俊彪，李苏，卢华正，陈䂀 (2015). 哀牢山中山湿性常绿榈叶林两种优势幼苗C、 $\mathrm{N} 、 \mathrm{P}$ 化学计量特征及其对 $\mathrm{N}$ 沉降增加的响应. 植物生态 学报, 39, 962-970.]

Tian HQ, Chen GS, Zhang C, Melillo JM, Hall CAS (2010). Pattern and variation of C:N:P ratios in China's soils: A synthesis of observational data. Biogeochemistry, 98, 139151.

Wardle DA, Gundale MJ, Jaderlund A, Nilsson MC (2013). Decoupled long-term effects of nutrient enrichment on aboveground and belowground properties in subalpine tundra. Ecology, 94, 904-919.

Yang XX, Ren F, Zhou HK, He JS (2014). Responses of plant community biomass to nitrogen and phosphorus additions in an alpine meadow on the Qinghai-Xizang Plateau. Chinese Journal of Plant Ecology, 38, 159-166. (in Chinese with English abstract) [杨晓霞, 任飞, 周华坤, 贺金生 (2014). 青藏高原高寒草甸植物群落生物量对氮、磷添 加的响应. 植物生态学报, 38, 159-166.]

Yang YH, Fang JY, Ji CJ, Datta A, Li P, Ma WH, Mohammat A, Shen HH, Hu HF, Knapp BO, Smith P (2014). Stoichiometric shifts in surface soils over broad geographical scales: Evidence from China's grasslands. Global Ecology and Biogeography, 23, 947-955.

Yu Q, Wu HH, He NP, Lü XT, Wang ZP, Elser JJ, Wu JG, Han XG (2012). Testing the growth-rate hypothesis in vascular plants with above- and below-ground biomass. PLOS ONE, 7, e32162. doi: 10.1371/journal.pone.0032162.

Yuan ZY, Chen HYH (2015). Decoupling of nitrogen and phosphorus in terrestrial plants associated with global changes. Nature Climate Change, 5, 465-469.

Zhao YF, Xu FL, Wang WL, Wang LL, Wang GX, Sun PY, Bai XF (2014). Seasonal variation in contents of C, N and $\mathrm{P}$ and stoichiometry characteristics in fine roots, stems and needles of Larix principis-rupprechtii. Chinese Bulletin of Botany, 49, 560-568. (in Chinese with English abstract) [赵亚芳, 徐福利, 王渭玲, 王玲玲, 王国兴, 孙鹏跃, 白小芳 (2014). 华北落叶松根茎叶碳氮磷含量及其化 学计量学特征的季节变化. 植物学报, 49, 560-568.]

Zhu FF, Yoh M, Gilliam FS, Lu XK, Mo JM (2013). Nutrient limitation in three lowland tropical forests in southern China receiving high nitrogen deposition: Insights from fine root responses to nutrient additions. PLOS ONE, 8, e82661. doi:10.1371/journal.pone.0082661.

责任编委: 王锁民 责任编辑: 王 蒇 